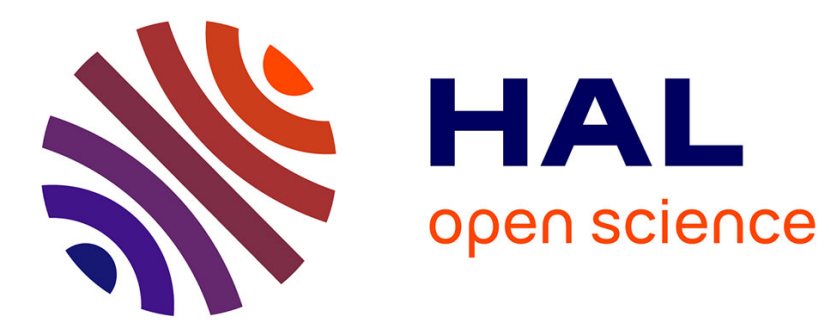

\title{
Variability of CO concentrations in the Venus troposphere from Venus Express/VIRTIS using a band ratio technique
}

C.C.C. Tsang, F.W. Taylor, C.F. Wilson, S.J. Liddell, P.G.J. Irwin, G. Piccioni, P. Drossart, S.B. Calcutt

\section{To cite this version:}

C.C.C. Tsang, F.W. Taylor, C.F. Wilson, S.J. Liddell, P.G.J. Irwin, et al.. Variability of CO concentrations in the Venus troposphere from Venus Express/VIRTIS using a band ratio technique. Icarus, 2009, 201 (2), pp.432. 10.1016/j.icarus.2009.01.001 . hal-00533496

\section{HAL Id: hal-00533496 https://hal.science/hal-00533496}

Submitted on 7 Nov 2010

HAL is a multi-disciplinary open access archive for the deposit and dissemination of scientific research documents, whether they are published or not. The documents may come from teaching and research institutions in France or abroad, or from public or private research centers.
L'archive ouverte pluridisciplinaire HAL, est destinée au dépôt et à la diffusion de documents scientifiques de niveau recherche, publiés ou non, émanant des établissements d'enseignement et de recherche français ou étrangers, des laboratoires publics ou privés. 


\section{Accepted Manuscript}

Variability of $\mathrm{CO}$ concentrations in the Venus troposphere from Venus Express/VIRTIS using a band ratio technique

C.C.C. Tsang, F.W. Taylor, C.F. Wilson, S.J. Liddell, P.G.J. Irwin, G. Piccioni, P. Drossart, S.B. Calcutt

PII: $\quad$ S0019-1035(09)00010-4

DOI: $\quad$ 10.1016/j.icarus.2009.01.001

Reference: $\quad$ YICAR 8877

To appear in: Icarus

Received date: 5 August 2008

Revised date: 4 December 2008

Accepted date: 8 January 2009

Please cite this article as: C.C.C. Tsang, F.W. Taylor, C.F. Wilson, S.J. Liddell, P.G.J. Irwin, G. Piccioni, P. Drossart, S.B. Calcutt, Variability of CO concentrations in the Venus troposphere from Venus Express/VIRTIS using a band ratio technique, Icarus (2009), doi: 10.1016/j.icarus.2009.01.001

This is a PDF file of an unedited manuscript that has been accepted for publication. As a service to our customers we are providing this early version of the manuscript. The manuscript will undergo copyediting, typesetting, and review of the resulting proof before it is published in its final form. Please note that during the production process errors may be discovered which could affect the content, and all legal disclaimers that apply to the journal pertain. 


\title{
Variability of CO concentrations in the Venus troposphere from Venus Express/VIRTIS using a Band Ratio Technique
}

\author{
C.C.C. Tsang ${ }^{\mathrm{a}}$, F.W. Taylor ${ }^{\mathrm{a}}$, C.F. Wilson ${ }^{\mathrm{a}}$, S.J. Liddell ${ }^{\mathrm{a}}$, \\ P.G.J. Irwin ${ }^{\mathrm{a}}$, G. Piccioni ${ }^{\mathrm{b}}$, P. Drossart ${ }^{\mathrm{c}}$, S.B. Calcutt ${ }^{\mathrm{a}}$ \\ ${ }^{a}$ Atmospheric, Oceanic and Planetary Physics, Department of Physics, University of Oxford, Parks \\ Road, Oxford, Oxon, OX1 3PU, U.K. \\ ${ }^{\mathrm{b}}$ INAF-IASF, Via del Fosso del Cavaliere, 10000133 Rome, Italy \\ ${ }^{c}$ LESIA, Observatoire de Paris, CNRS, UPMC Université Paris-Diderot \\ Number of Manuscript Papers: $9+$ references, figures (22 in total) \\ Number of Tables: 1 \\ Number of Figures: 12 \\ Proposed Running Head: \\ Band Ratio Technique of CO on Venus \\ Editorial correspondence should be directed to: \\ Dr Constantine C.C. Tsang \\ Atmospheric, Oceanic and Planetary Physics, Department of Physics, University of \\ Oxford, Clarendon Laboratory, Parks Road, Oxford, Oxon, OX1 3PU, Oxford, \\ United Kingdom. \\ Tel:(+44) 1865 272927, Fax: (+44) 1865272923 \\ Email:con@atm.ox.ac.uk
}

Keywords:

Venus, Venus Express, Dynamics, Carbon Monoxide, Troposphere

\begin{abstract}
A fast method is presented for deriving the tropospheric $\mathrm{CO}$ concentrations in the Venus atmosphere from near-infrared spectra using the night side $2.3 \mu \mathrm{m}$ window. This is validated using the spectral fitting techniques of Tsang et al. (2008a) to show that monitoring CO in the deep atmosphere can be done quickly using large numbers of observations, with minimal effect from cloud and temperature variations. The new method is applied to produce some 1,450 zonal mean $\mathrm{CO}$ profiles using data from the first eighteen months of operation from the Visible and Infrared Thermal Imaging Spectrometer infrared mapping subsystem (VIRTIS-M-IR) on Venus Express. These results show many significant long and short-term variations from the mean equator-to-pole
\end{abstract}


increasing trend previously found from earlier Earth- and space-based observations, including a possible North-South dichotomy, with interesting implications for the dynamics and chemistry of the lower atmosphere of Venus.

\section{Introduction}

The concentration of carbon monoxide (CO) in the troposphere (surface to $40 \mathrm{~km}$ ) of Venus was first proposed to be retrievable through modeling by Kamp et al. (1988). This is possible through the observation of the thermal emission window at $2.3 \mu \mathrm{m}$, where the radiation is escaping from the deep atmosphere. For a thorough review of this topic, see Taylor et al. (1997) and Tsang et al. (2008b). The first measurements of CO using this window were made by Bézard et al. (1990) from CFHT observations. Pollack et al. (1993) also conducted ground-based observations to measure the mean abundance of $\mathrm{CO}$ in the troposphere. However, the first attempt to measure spatial variations in CO at $35 \mathrm{~km}$ was by Collard et al. (1993), using $2.3 \mu \mathrm{m}$ spectra obtained by the Near Infrared Mapping Spectrometer (NIMS) on the Galileo spacecaft.

\subsection{Collard et al. 1993 Method}

These authors used Galileo/NIMS spectra at $2.3 \mu \mathrm{m}$ from the fly-by of Venus in 1990. Rather than using a spectral fitting technique, Collard et al. (1993) used ratios of radiances at two different wavelengths. Between 2.20 and $2.30 \mu \mathrm{m}$, the absorption is purely due to $\mathrm{CO}_{2}$ and cloud opacity, whilst at 2.30 to $2.43 \mu \mathrm{m}$, the absorption is due to strong vibrational-rotation $\mathrm{CO}$ bands as well. The wavelengths chosen by the authors were $2.252 \mu \mathrm{m}$, outside the CO band, and $2.330 \mu \mathrm{m}$, with strong $\mathrm{CO}$ absorption. A distinct correlation is observed between these two wavelengths, which is due to the optical depth of the cloud layer, as one might expect. However, an off-branching set of points was also seen beneath the main branch. This was interpreted as being due to the increase in the CO abundance at these locations on the planet, causing the increased absorption at $2.330 \mu \mathrm{m}$ compared to the 'nominal'. After drawing an arbitrary line bisecting the cloud opacity points and the points due to increased $\mathrm{CO}$, an enhancement was seen poleward of $47^{\circ} \mathrm{N}$. It was thus shown that a CO latitudinal gradient exists in the lower atmosphere. Extensive studies were conducted by the above authors to investigate the possibility that the bifurcation was due to other effects such as variations in temperature profiles, emission angles and differing cloud structures, all of which proved negative.

\subsection{Ground-Based Observations and Venus Express}

Since the work of Collard et al. (1993), numerous ground-based studies have been conducted, most notably Marcq et al. $(2005,2006)$, in order to confirm the existence of the trospospheric CO gradient and to better elucidate its nature. Whilst their measurements were in line with the expected gradients and values seen by Galileo/NIMS, they did not manage to yield information as to the temporal and zonal distribution of $\mathrm{CO}$ at this altitude of $35 \mathrm{~km}$, due to their high spectral, but therefore low spatial, resolutions. Observations took on a new facet with the arrival of Venus Express and its array of instruments around Venus in 2006, which allowed the possibility of retrieving and thus monitoring $\mathrm{CO}$ in the troposphere with good spatial and temporal coverage. On board was an imaging spectrometer, VIRTIS (Drossart et al. 2007, Piccioni et al. 2008). The subsystems on VIRTIS, called H (high resolution spectrograph of $1 \mathrm{~nm}$ spectral sampling) and MIR (low resolution spectral imager with $10 \mathrm{~nm}$ spectral sampling), are able to sample the $2.3 \mu \mathrm{m}$ thermal emission, amongst others. VIRTIS-M-IR has a spectral range from 1.01 to $5.19 \mu \mathrm{m}$, divided into 432 discrete spectral bands (Band 0 to Band 431). 
Marcq et al. (2008) were able to retrieve the abundance and the latitudinal gradient of CO using the $\mathrm{H}$ subchannel to good precision, whilst Tsang et al. (2008a) used the M imaging channel to retrieve spatial maps to look for spatial and temporal variations, without substantial loss in precision. Tsang et al. (2008a) showed the latitudinal variations as expected. However, due to the complex and time consuming spectral fitting of the CO 2-0 band required for the analysis, only four observations were analysed. These observations, although limited in time, did show interesting and significant signs of zonal and temporal variability. A faster, but still accurate, method is thus required to derive and monitor variations in the $\mathrm{CO}$ concentration. This was the main motivation for this analysis. Section 2 will deal with the drawbacks of the Collard et al. (1993) method, followed by our new method, with forward modeling. Section 3 contains the results and Section 4 the conclusions of this analysis.

\section{Analysis}

\subsection{Ratio Methodology}

The premise for this analysis was to repeat the experiment of Collard et al. 1993 described in Section 1.1 , by taking radiation emitted at $2.30 \mu \mathrm{m}$, which should be sensitive only to cloud opacity and compare it to the radiation emitted at 2.32 or $2.33 \mu \mathrm{m}$, which is attenuated by $\mathrm{CO}$ as well as cloud opacity. Fig. 1 shows how synthetic spectra behave when we artificially increase the abundance of CO in the deep atmosphere. We shall return to this in Section 2.2.3.

As we followed the approach mentioned above, it became clear it was not accurate enough for our purpose. Fig. 2 shows the result from using the method on VIRTIS-M-IR observation; VI099_2, corresponding to orbit number 99 , cube 2 , is used as a case study. When we plot radiances from Band 135 versus Band 137, which correspond to wavelengths of 2.30 and $2.32 \mu \mathrm{m}$, two general trends appear, which mimic the observation by Collard et al. (1993). The reasons for choosing these two wavelengths will be given in Section 2.2. We then choose an arbitrary straight line to bisect the points due to $\mathrm{CO}$ and those from cloud opacity. The displacement of the points from the straight line is then plotted as a function of their latitude position, and compared with the $2.30 \mu \mathrm{m}$ radiances, which are a direct indication of cloud opacity. Firstly, we see that the displacement as a function of latitude increases towards the poles. This is in line with what is expected of the CO latitudinal structure (Marcq et al. 2008a, Tsang et al. 2008a). However, comparison with $2.30 \mu \mathrm{m}$ radiances also shows an anti-correlation with the cloud opacity. Clearly, this is not an accurate method of retrieving $\mathrm{CO}$ in the lower atmosphere, as the $\mathrm{CO}$ abundance should be decoupled from variations in the overlying cloud layers. The problem comes from the selection of the straight line, which is arbitrary, and has no physical basis. Therefore, we have propose an alternative, and simpler method.

Fig. 3 shows the result of a direct division of the radiances at Band 135 with Band 137 [2.300/2.320 $\mu \mathrm{m}]$ using the same dataset as before. The result is a trend in the expected direction, increasing from equator to pole, peaking at $65{ }^{\circ} \mathrm{S}$, but in this instance, there is no discernable correlation between the ratio values using this division method and the $2.3 \mu \mathrm{m}$ radiances. We then plot the zonal mean value of the Band135/Band137 ratio and the $2.30 \mu \mathrm{m}$ radiance, with their $1 \sigma$ standard deviation from the mean as error bars. This gives a value for the variation of the cloud opacity and $\mathrm{CO}$ value at that latitude. We shall now present some forward modelling calculations to show that this ratio is an excellent proxy for the tropospheric $\mathrm{CO}$ abundances.

\subsection{Forward Modelling and Retrieval Comparison}


A forward model was used to generate synthetic spectra between 2.18 and $2.50 \mu \mathrm{m}$ under different conditions to confirm the ratio mentioned above is indeed sensitive primarily to $\mathrm{CO}$ enhancements. The forward model, which is described fully in Tsang et al. (2008b) and Irwin et al. (2008), uses the correlated-k approach to pre-tabulate the absorption coefficient for gaseous species, which is then used to calculate the transmission through the atmosphere. We use the HITEMP linelist for $\mathrm{CO}_{2}$, with a collision induced absorption coefficient of $4.0 \times 10^{-8} \mathrm{~cm}^{-1} /$ amagat $^{2}$ in this spectral window. The temperature profile has been taken from Seiff (1983), and the nominal cloud profile has been taken from Pollack et al. (1993). We assume a $75 \% \mathrm{H}_{2} \mathrm{SO}_{4}$ to $25 \% \mathrm{H}_{2} \mathrm{O}$ concentration for the sulphuric acid clouds, using Palmer and Williams (1975) for the refractive indices. We use a 10stream matrix operator model to account for multiple-scattering events in the atmosphere, with 111 vertical scattering layers. Using this model, a number of different tests were conducted in order to show the only significant effect on the $2.30 / 2.32 \mu \mathrm{m}$ radiance is the $\mathrm{CO}$ abundance in the troposphere.

\subsubsection{Changes in Cloud Profile}

A major effect on the outgoing radiances at these near infrared wavelengths is due to cloud opacity, which changes rapidly across the planet. We adopt the cloud model described in Pollack et al. (1993). There are four different modes, with radius of $0.5,1.0,1.2$ and $3.0 \mu \mathrm{m}$. We have modelled different opacities of clouds to better understand its effects on the ratio of radiances 2.30/2.32. The results can be seen in Fig. 4, where the cloud opacity is plotted as a function of the 2.30 peak radiances. The observed $2.3 \mu \mathrm{m}$ radiances observed by VIRTIS range from 0.001 to $0.3 \mathrm{~W} / \mathrm{m}^{2} / \mathrm{sr} / \mu \mathrm{m}$ corresponding to the darkest and brightest regions of cloud. As we increase the opacity of the clouds, we see the value of the ratio remains constant (no correlation) but then moves gradually such that a direct relationship between the ratio and cloud opacity occurs under extremely large optical depths. However, there is little correlation in the radiance region seen from the VIRTIS-M data, until the clouds are so thick that the $2.3 \mu \mathrm{m}$ radiance is less than $0.02 \mathrm{~W} / \mathrm{m}^{2} / \mathrm{sr} / \mu \mathrm{m}$. In radiances above this limit, there is less than a $10 \%$ error on the ratio caused by cloud opacity. We shall see that this is small compared to the signal due to CO. Ultimately, the choice of the wavelength pairs, in our case 2.30 and $2.32 \mu \mathrm{m}$, comes from a compromise between a good sensitivity to $\mathrm{CO}$, where the peak sensitivity occurs at $2.33 \mu \mathrm{m}$, and the sensitivity to the non-grey absorption of $\mathrm{H}_{2} \mathrm{SO}_{4}$, which increases as we increase the separation of the wavelength pairs. Indeed, if we chose $2.30 / 2.31 \mu \mathrm{m}$, the relationship of this wavelength pair would be even more independent of cloud opacity, but we forfeit our sensitivity to CO. The converse is true for the $2.30 / 2.33 \mu \mathrm{m}$ pair; and thus we arrive at the compromise wavelength pair of $2.30 / 2.32 \mu \mathrm{m}$. These alternate wavelength pairs are also plotted in Fig. 4.

\subsubsection{Temperature and emission angle effects}

It can be seen in Tsang et al. (2008b) that the effect of idealised changes in the vertical temperature profile at $30^{\circ}$ latitude to that at $80^{\circ}$ at $2.30 \mu \mathrm{m}$ is to cause less than a $10 \%$ change in the outgoing radiances. Even so, these latitudinal temperature profiles deviate from each other at heights greater than $\sim 45 \mathrm{~km}$, above the peak of the weighting function at $2.3 \mu \mathrm{m}$. We also do not expect a significantly large variation from the adiabat in this region of the atmosphere. Effects of variations in the emission angle have also been tested. Fig. 5 shows the model calculations to investigate the effect of changing the emission angle on the ratio. Different assumed a priori were tested: 1) the nominal profile described in Section $2.2,2) \mathrm{CO}$ vertical profiles scaled by factors of one half and two, 3) a cloud model with opacity 5\% and $200 \%$ of the nominal Pollack et al. 1993 profile, and 4) a much cooler temperature profile (from Tsang et al. 2008a) which might be more indicative of the temperature structure at the polar regions. All other variables in the profiles are as the nominal 
profile. Because Band 135 and Band 137 are close in wavelength, the variation of radiances as a function of $\cos \theta$, where $\theta$ is the emission angle, is the same. The change in the ratio value as a function of emission angle, from $0^{\circ}$ to $85^{\circ}$, is less than $1 \%$ for all the profiles. It is also satisfying to see that large changes in the cloud optical depth and temperature profile away from the nominal case have a much smaller effect on the ratio than changes in the CO concentration.

\subsubsection{Conversion of Radiance Ratio to CO}

Having shown that cloud opacity and mode variations, temperature and emission angle effects can all be neglected as the prime cause of the trends seen in the ratio as a function of latitude, we now model the remaining effect on this ratio: the $\mathrm{CO}$ vertical profile. Fig. 1 and 6 shows the effect of changes in the vertical $\mathrm{CO}$ volume mixing ratio (ppmv) on the radiance in the $2.3 \mu \mathrm{m}$ emission window. The modelled concentrations are plotted against the ratio of the radiances at wavelengths 2.30 and $2.32 \mu \mathrm{m}$. The nominal vertical profile is the same as the one used in Tsang et al. 2008a and is scaled from $50 \%$ to $120 \%$, in $10 \%$ increments, yielding CO ppmv values at $35 \mathrm{~km}$ from 13.8 to 33.2. The spectra have been calculated with a Full Width Half Maximum (FHWM) of $17 \mathrm{~nm}$, which is the width of the spectral profile seen in flight (private comm. with B. Bézard and G. Piccioni) (i.e.: spectral bin is $10 \mathrm{~nm}$, but the spectral resolution is $17 \mathrm{~nm}$ ). We can see from Fig. 6 a direct linear correlation exists between CO abundance in ppmv in the model atmosphere and the 2.30/2.32 $\mu \mathrm{m}$ radiance ratio, allowing a direct conversion between the two. It should also be noted from Figs. 4 and 6 that the slight dependence of the ratio to cloud opacity above $0.02 \mathrm{~W} / \mathrm{m}^{2} / \mathrm{sr} / \mu \mathrm{m}$ of \pm 0.2 ratio units equates to a conservative error of $\pm 4 \mathrm{ppmv}$ in the $\mathrm{CO}$ abundance.

\subsubsection{Comparison with Retrieval by Spectral Fitting}

As a test of this conversion of radiance ratio to ppmv, we can compare, for a given observation, the 2.30/2.32 zonal mean ratio to that of the zonal mean retrieved through spectral fitting. The results for this test case are given in Fig. 7. The spatial map of CO at $35 \mathrm{~km}$ for VI099_2, derived from Tsang et al. (2008a), is zonally averaged to yield a latitudinal trend. This is then compared to the 2.30/2.32 ratio and plotted together. The agreement is extremely good, allowing a direct validation of the relationship between the $\mathrm{CO}$ abundance (ppmv), and the radiance ratio. Examination of Fig. 7 shows a near perfect match between the zonal means at 40 to $55^{\circ} \mathrm{S}$, whilst the greatest difference occuring at 30 and $70^{\circ} \mathrm{S}$ differ by $2-3$ ppmv. The overlapping trends are in good agreement with the modelling described in the previous section. Therefore, we can be even more confident that the contrast seen in the 2.30/2.32 ratio is due primarily to $\mathrm{CO}$, rather than other factors.

\subsection{Wavelength Shift and Interpolation}

It has been known that a slight wavelength shift is detectable from different observations, as the temperature of the spectrometer changes slightly from orbit to orbit under different thermal conditions (priv. comms. with G. Piccioni and P. Drossart). This effect has not been fully calibrated out of the data and was studied by Bezard et al. (2008), using the $1.74 \mu \mathrm{m}$ window, which probes at a height approximately $15 \mathrm{~km}$. The mean spectral shift was seen to change on the order of 4-10 nm ( 1 bin size $=10 \mathrm{~nm}$ ) from observation to observation. In addition, the effect was also spatially dependent (i.e.: the shift was different at the edge of the detector compared to the centre). Also, the spectral shift for a particular observation was slightly different depending on which wavelength region was under study. Therefore, one should not rely solely on a single $2 \mathrm{D}$ wavelength shift applied to a single observation for all wavelengths. This instrumental effect must be taken into account before proceeding with the band-ratio technique. 
To work out the spectral shift at $2.3 \mu \mathrm{m}$ on a pixel-to-pixel basis, we generate a synthetic spectrum using the model described by Tsang et al. $2008 \mathrm{~b}$, with nominal clouds and full Mie scattering with assumed a priori temperature and gaseous concentrations. This spectrum is then normalised and compared to the normalised spectra taken between Bands 122 and Bands 155, which covers the 2.3 $\mu \mathrm{m}$ window, in the image. We then use a cross-correlation algorithm (Research Systems 2000), to find the wavelength shift which best matches the shift of the real spectrum to that of the reference spectrum. We do this for all points on the image. We assume the spectral shift is constant in the 2.3 $\mu \mathrm{m}$ window, and thus the two-dimensional shift map is applied to all spectral points in this window. However, since we want radiances that are exactly 2.300 and $2.320 \mu \mathrm{m}$ (producing ratios we can convert to ppmv and thus comparable from observation to observation), we also interpolate the radiances to those wavelengths. All results given below have been wavelength adjusted and interpolated to exactly 2.300 and $2.320 \mu \mathrm{m}$.

\section{Results}

\subsection{Data Set Used}

The method described above has been used to analyse all VIRTIS observations with integration times of $3 \mathrm{~s}$ and greater that were obtained during Venus Express operations from the time of orbit insertion (16 ${ }^{\text {th }}$ April 2006) to $11^{\text {th }}$ November 2007 (Titov et al., 2006). This corresponds to some 1,450 spectral images, each producing a CO map and a zonal mean CO profile. Table 1 gives a summary of the observations used, which includes a total of 82 Northern Hemisphere observations. An observation is defined as a single 3D (two spatial, one spectral) image cube. Several observations are taken during a single orbit. Refer to Titov et al., 2006 for additional clarity.

\subsection{Variability}

Fig. 8 shows two observations: VI0336_00, a 3.3 s exposure image cube taken on the $22^{\text {nd }}$ March 2007, and VI0392_05, an 8 second exposure image cube taken on the 17th May 2007. Fig. 9 shows another two observations, VI0301_00 and VI0381_00, both 3.3 s exposures taken on the 15th February and $6^{\text {th }}$ May 2007 respectively. All four observations are $256 \times 256$ pixels, cover the Southern Hemisphere including high latitudes, and are typical of the data used in this analysis. As expected from the analysis shown in Fig. 3, they all show little correlation with the $2.3 \mu \mathrm{m}$ cloud opacity variations in the mid-latitude region, all of the significant variability being due to CO. However, near the pole (latitude $>70{ }^{\circ} \mathrm{S}$ ) where the radiance falls below the $0.02 \mathrm{~W} / \mathrm{m}^{2} / \mathrm{sr} / \mu \mathrm{m}$ threshold at $2.3 \mu \mathrm{m}$, indicating very thick clouds, the effect of cloud opacity becomes important.

In both of the examples shown in Fig. 8 , the $2.3 / 2.32 \mu \mathrm{m}$ radiance ratio shows an increase in value with latitude, peaking at $65{ }^{\circ} \mathrm{S}$, and the $\mathrm{CO}$ abundance rises from the equator and attains a maximum value at $65^{\circ} \mathrm{S}$ of $\sim 33 \pm 4$ ppmv in both observations. When the longitudinal variability first noted by Tsang et al. (2008a) is taken into account, this behaviour and these values are typical of those found in the low-resolution ground-based and Galileo NIMS data discussed above in the introduction. However, in the long, high-resolution data set analysed here we find that examples occur when the equator-to-pole gradient in $\mathrm{CO}$ is almost completely absent: two of these are shown in Figure 9. The distribution of CO in the observation VI0301_00 has a mean value of $\sim 24 \pm 4$ ppmv rising to 26 at $60{ }^{\circ} \mathrm{S}$, i.e. is essentially flat. VI0381_00 again shows a flat field for CO, and has an even lower abundance of $\sim 23 \pm 4$ ppmv from 40 to $65^{\circ} \mathrm{S}$, approximately the expected value at the equator.

293 
In the past, the trend of increasing $\mathrm{CO}$ from equator to pole has been taken to be a characteristic feature of the Venus atmosphere, related to its general circulation (see e.g. Taylor, 2006). The degree of temporal variability reported here has never been seen before and so is both unexpected and intriguing. The current hypothesis was that a hemispherical 'Hadley' circulation brings CO rich air down from the mesosphere $(\sim 65 \mathrm{~km})$ to the troposphere $(\sim 35 \mathrm{~km})$ at high latitudes. However, the variability seen in our new results would seem to be too large and too rapid to be consistent with such a simple picture. The lack of any CO gradient, if it applied to the whole hemisphere, would imply that transport in the Hadley cell had essentially ceased, while even smaller fluctuations in the global-scale flux might be expected to take more than a few days. Yet the elapsed time between VI0381_00 and VI0392_05, for instance, is only about 11 (Earth) days.

It seems more reasonable to speculate that the net meridional circulation on Venus is more asymmetric than a simple Hadley cell, a possibility that is supported by the zonal variation that can be seen in the images in Figs. 8 and 9. There may also be implications for the chemical processes which lead to the destruction of $\mathrm{CO}$ as it descends from the main source in the mesosphere to the main sink regions in the clouds and at the surface, but it may also imply that the strength of the downwelling might be variable. Another possibility is that we are seeing different phases of the spatial variability locked to a planetary wave feature, which prevails in the lower atmosphere, moving horizontally. We thus might be seeing the maximum (Fig. 8) and minimum (Fig. 9) of the wave feature at different times and locations. This possibility is difficult to investigate with the data set used here, because of a lack of systematic coverage due to the operating modes of the Venus Express payload (Titov et al., 2006). However, the spacecraft, and VIRTIS, are still operating at the time of this writing and further investigations can be conducted to search for systematic behaviour in the CO distribution. Finally, recent work by Marcq et al. (priv. comms.) using passive tracers in a General Circulation Model of Venus have tentatively shown zonal variability in the CO abundances at $35 \mathrm{~km}$. In some of these simulations, the equator-pole gradient is much reduced and it is very likely that we are observing at these locations. The processes involved to produce such a picture are not fully understood, but must involve a complex interplay between the general circulation, the lifetime of $\mathrm{CO}$ and perhaps other factors such as the topography of the surface.

\subsection{Zonal mean CO profiles}

The zonal means show the divergence of the $\mathrm{CO}$ abundance from the mean trends more clearly than global maps. Fig. 10 shows the ratio of the radiances at $2.30 / 2.32 \mu \mathrm{m}$ vs. latitude for four sequential observations spanning three orbits, with Fig. 10 showing a further 10 observations. Fig.10 also shows the $2.3 \mu \mathrm{m}$ radiances, which show large fluctuations produced by cloud opacity. These fluctuations are not mimicked by the radiance ratios, again showing this method of generating the $\mathrm{CO}$ abundance is effectively decoupled from the cloud morphology except near the poles where the clouds are highly opaque. It should also be noted that the $0.02 \mathrm{~W} / \mathrm{m}^{2} / \mathrm{sr} / \mu \mathrm{m}$ threshold at which the $\mathrm{CO}$ retrieval becomes contaminated by cloud opacity is rarely reached in these observations.

The $\mathrm{CO}$ abundance shows the marked poleward increase, from $22 \mathrm{ppm}$ at the equator to $30 \mathrm{ppm}$ at the $60{ }^{\circ} \mathrm{S}$, expected of tropospheric $\mathrm{CO}$ seen prior to the present work. Our contemporaneous observations of both hemispheres show the degree of dichotomy between the hemispheres. The Northern Hemisphere shows a maximum in CO abundance of $29 \pm 3 \mathrm{ppm}$, whilst the Southern Hemisphere reaches $32 \pm 3 \mathrm{ppm}$. The degree of variability in location and magnitude of the $\mathrm{CO}$ maximum can be seen most clearly in Fig. 11, which shows the Northern and Southern Hemispheres seen in sequential observations. Over the space of two orbits, we can see the maximum $\mathrm{CO}$ abundance in the North vary from $35 \pm 3 \mathrm{ppm}$ (top), to as low as $27 \pm 3 \mathrm{ppm}$ (bottom), while a smaller variation is seen in the South. However, following on from the discussion 
above, it is difficult to be sure at present whether there is a real North-South dichotomy, or whether these results reflect the natural variability in the deep $\mathrm{CO}$ abundance.

\subsection{Ensemble Mean}

Fig. 12 is the ensemble of the zonal mean ratios derived from all of the 1,450 CO observations in Table 1 . This gives a good impression of the degree of variability over the 18 -month period relative to the large-scale temporal mean. There are some $80+$ observations of the Northern Hemisphere, leaving the remaining large majority in the South. In the ensemble mean, the Southern Hemisphere $\mathrm{CO}$ maximum peak at $65^{\circ} \mathrm{S}$ is approximately $35 \pm 3 \mathrm{ppm}$, whilst the Northern Hemisphere attains $30 \pm 3 \mathrm{ppm}$ for the same latitude. This modest hemispherical asymmetry may, however, be due to the less frequent sampling of the Northern Hemisphere, a consequence of the orbit of Venus Express. Scrutiny of Fig. 12 shows that there was one observation of the Northern hemisphere when the $\mathrm{CO}$ maximum was as high as the highest seen at any time in the South, suggesting that the relative shortage of high values in the coverage of the North is fortuitous.

The ensemble mean also emphasizes the decrease of abundance polewards of $65^{\circ}$ latitude in both hemispheres, as was seen by Tsang et al. (2008a) and Marcq et al. (2008). However, since the radiances near $2.3 \mu \mathrm{m}$ at these high latitudes are small, the contribution from the CO below the clouds to the spectrum is also small and the signal-to-noise ratio correspondingly low. This makes the $2.30 / 2.32 \mu \mathrm{m}$ ratio more dependent on the cloud opacity than the CO mixing ratio and reduces confidence in the retrievals which indicate that the polar concentrations of $\mathrm{CO}$ are lower than the peak value of 30-35 ppm.

\section{Conclusions}

The first focus of this analysis was to show that the measured ratio of thermal emission from the nightside of Venus in the 2.30 and $2.32 \mu \mathrm{m}$ spectral bands can yield good estimates of the abundance of tropospheric CO. Forward modelling to test the effects of changes in the temperature profile and the cloud optical depth showed little detrimental effect on the CO retrieval by this method. Direct comparison with CO profiles obtained from the full spectral modeling approach of Tsang et al. (2008a) confirmed that the ratio method gave results which, while marginally less accurate than full accurate spectral fitting retrievals, do allow large number of datasets to be analyzed quickly. In addition to the interpretation to Venus Express VIRTIS data discussed here, the technique is currently being applied to ground-based telescopic image cubes taken from both NASA IRTF/SpeX (E. Young priv. comm.) and the Anglo-Australian Telescope (J. Bailey priv. comm.). It should also be valuable for the future Japanese mission Planet-C to Venus, which will fly an IR imaging camera at wavelengths sensitive to CO (Nakamura et al. 2007).

The analysis of 1,450 observations of nightside spectral cubes from VIRTIS-M on Venus Express has shown significant, previously unseen temporal and spatial variations in the abundance of CO. It is not clear at present whether these new data are compatible with the previously widely accepted notion that Venus has a hemispherical Hadley-type circulation and that this carries CO into the troposphere from the mesosphere where $\mathrm{CO}$ is produced in large quantities by the photolysis of carbon dioxide. At the very least, such a model will need to be extensively modified to include time-dependent and latitudinally-variable processes that significantly affect the production and removal of carbon monoxide in Venus' atmosphere. 


\section{Acknowledgements}

We acknowledge the contributions in discussion with Emmanuel Marcq, Bruno Bezard, Bob Carlson, Jeremy Bailey and Eliot Young. This work would not have been possible without the funding from the Science Technology and Facility Council (STFC). We also thank the support of ASI and CNES.

\section{References}

Bezard B, de Bergh C, Crisp D, Maillard J. (1990), The deep atmosphere of Venus revealed by high-resolution nightside spectra. Nature, Vol. 345, 508-511

Bezard B., Tsang C.C.C., Carlson R.W., Piccioni G., Marcq, E., and Drossart P., (2008), The water vapour abundance near the surface of Venus with Venus Express/VIRTIS Observations, Journal of Geophys. Res., (Submitted).

Collard A. D., Taylor F.W., Calcutt S.B., Carlson R.W., Kamp L.W., Baines K.H., Encrenaz, Th., Drossart P., Lellouch E. and Bezard B., (1993), Latitudinal distribution of carbon monoxide in the deep atmosphere of Venus. Planetary and Space Science, Vol. 41(7), 487-94

Drossart, P., Piccioni, G., Adriani, A., Angrilli, F., Arnold, G., Baines, K., Bellucci, G., Benkhor, J., Bezard, B., Bibring, J.-P., Blanco, A., Blecka, M., Carlson, R., Coradini, A., Di Lellis, A., Encrenaz, T., Erard, S., Fonti, S., Formisano, V., Fouchet, T., Garcia, R., Haus, R., Helbert, J., Ignatiev, N., Irwin, P., Langevin, Y., Lebonnois, S., Lopez-Valverde, M., Luz, D., Marinangeli, L., Oro ${ }^{-}$no, V., Rodin, A., Roos-Serote, M., Saggin, B., Sanchez-Lavega, A., Stam, D., Taylor, F., Titov, D., Visconti, G., Zambelli, M., Hueso, R., Tsang, C.C.C., Wilson, C. and Afanasenko, T. Z. (2007), 'Scientific goals for the observation of Venus by VIRTIS on ESA/Venus Express mission', Planetary and Space Science, Vol 55, 1653-1672.

Irwin P.G.J., Teanby N.A., de Kok R., Fletcher L.N., Howett C.A., Tsang C.C.C., Wilson C.F., Calcutt S.B., Nixon C.A., Parrish P.D., (2008), The NEMESIS planetary atmosphere radiative transfer and retrieval tool, Journal of Quantitative Spectroscopy and Radiative Transfer, Vol. 109, Pg 1136-1150, doi:10.1016/j.jgsrt.2007.11.006

Kamp, L., Taylor, F. and Calcutt, S. (1988), 'Structure of Venus's atmosphere from modelling of night-side infrared spectra.', Nature, 336, 360-362.

Marcq, E., B. Bezard, T. Encrenaz, and M. Birlan (2005), Latitudinal variations of CO and OCS in the lower atmosphere of Venus from near-infrared nightside spectro-imaging, Icarus, 179, 375-386, doi:10.1016/j.icarus.2005.06.018.

Marcq, E., T. Encrenaz, B. Bezard, and M. Birlan (2006), Remote sensing of Venus' lower atmosphere from ground-based IR spectroscopy: Latitudinal and vertical distribution of minor species, Planet. Space Sci., 54, 1360-1370, doi:10.1016/j.pss.2006.04.024.

Marcq, E., B. Bezard, P. Drossart, and G. Piccioni (2008), A latitudinal survey of CO, OCS, $\mathrm{H}_{2} \mathrm{O}$ and $\mathrm{SO}_{2}$ in the lower atmopshere of Venus: spectroscopic studies using VIRTIS-H, Journal of Geophys. Res., (In Press)

Nakamura, M. and. Imamura., T. and Ueno, M. and Iwagami, N. and Satoh, T. and Watanabe, S. 
and Taguchi, M. and Takahashi, Y. and and M. a. A. Suzuki, T. and Hashimoto, G.L. and Sakanoi, T. and Okano, S. and Kasaba, Y. and Yoshida, J. and Yamada, M. and Ishii, N. and Yamada, T. and Uemizu, K. and Fukuhara, T. and Oyama, K. (2007), Planet-C: Venus Climate Orbiter mission of Japan, Planetary and Space Science 55, 831-1842.

Palmer, K. and Williams, D. (1975), Optical Constants of Sulfuric Acid; Application to the Clouds of Venus?, Applied Optics 14(1), 208-219

Piccioni, G., Drossart P. and Suetta, E. and Cosi, M. and Ammannito, E. and Barbis, A. and Berlin, R. and Boccaccini, A. and Bonello, G. and Bouyé, M. and Capaccioni, F. and Cherubini, G. and Dami, M. and Dupuis, O. and Fave, A. and Filacchione, G. and Hello, Y. and Henry, F. and Hofer, S. and Huntzinger, G. and Melchiorri, R. and Parisot, J. and Pasqui, C. and Peter, G. and Pompei, C. and Rèess, J.M. and Semery, A. and Soufflot A. and the Venus Express/VIRTIS Team (2008). VIRTIS: The Visible and Infrared Thermal Imaging Spectrometer, ESA Special Publication, SP1295: 1-27.

Pollack, J., Dalton, J., Grinspoon, D., Wattson, R., Freedman, R., Crisp, D., Allen, D., Bezard, B., de Bergh, C. and Giver, L. (1993), Near-Infrared Light from Venus' Nightside: A Spectroscopic Analysis.', Icarus 103, 1-42

Research Systems (2000), IDL Reference Guide, IDL Version 5.4, September 2000 Edition, 139140

Seiff A. (1983), Thermal structure of the atmosphere of Venus. In: Hunten D, Colin L, Donahue T, Moroz V, editors. 'Venus'. Tucson, AZ, University of Arizona,. p. 215-79.

Taylor, F., Crisp, D. and Bezard, B. (1997), Near-Infrared Sounding of the Lower Atmosphere of Venus., in 'Venus II: Geology, Geophysics, Atmosphere, and Solar Wind Environment.', The University of Arizona Press., Tuscon, Arizona, pp. 325-351.

Taylor, F. W. (2006). "Venus before Venus Express." Planetary and Space Science 54: 1249-1262.

Titov, D. V. and. Svedhem, H. and Koschny, D. and Hoofs, R. and Barabash, S. and Bertaux, J.-P. and Drossart, P. and Formisano, V. and Hausler, B. and Korablev, O. and Markiewicz, W.J. and Nevejans, D. and Patzold, M. and Piccioni, G. and Zhang, T.L. and Merritt, D. and Witasse, O. and Zender, J. and Accomazzo, A. and Sweeney, M. and Trillard, D. and Janvier, M. and Clochet, A. (2006). Venus Express science planning, Planetary and Space Science, Vol. 54, pp. 1279-1297

Tsang C.C.C., Irwin P.G.J., Taylor F.W., Wilson C.F., Drossart P., Piccioni G., de Kok R., Lee C., Calcutt S.B. and the Venus Express/VIRTIS Team, (2008a), Tropospheric Carbon Monoxide Concentrations and Variability on Venus with Venus Express/VIRTIS-M Observations, Journal of Geophys. Res., (In Press), doi:10.1029/2008JE003089

Tsang C.C.C., Irwin, P.G.J., Taylor, F.W., Wilson C.F., (2008b), A Correlated-k Model of Radiative Transfer in the Near Infrared Windows of Venus, Journal of Quantitative Spectroscopy and Radiative Transfer, Vol. 109, Pg 1118-1135, doi:10.1016/j.jqsrt.2007.12.008 


\begin{tabular}{|c|c|c|c|c|c|}
\hline Observation & Int. Time: & Int. Time: & Int. Time: & Int. Time: & Presented Observations \\
\hline $\begin{array}{l}\text { Sequences } \\
\text { MTP01 }\end{array}$ & $3.0 \mathrm{~s}$ & $\begin{array}{c}3.3 \mathrm{~s} \\
13\end{array}$ & $8.0 \mathrm{~s}$ & $18.0 \mathrm{~s}$ & \\
\hline МТР02 & & 13 & & & $\begin{array}{l}\text { VI060_06, VI061_06, } \\
\text { VI066_00, VI066 } 01\end{array}$ \\
\hline МТР03 & & 133 & 14 & & $\begin{array}{l}\text { VI082_03, VI082_18, } \\
\text { VI083_02, VI099_02 }\end{array}$ \\
\hline MTP04 & & 189 & 6 & & \\
\hline МТP05 & & 196 & 2 & & $\begin{array}{l}\text { VI0148_15, VI0149_00, } \\
\text { VI0149_01, VI0149_02 }\end{array}$ \\
\hline МТР06 & & 20 & 11 & & \\
\hline МТР07 & & 5 & & & \\
\hline МТР08 & & 39 & & & \\
\hline МТР09 & & 70 & 3 & & \\
\hline MTP10 & & 33 & 6 & & \\
\hline MTP11 & & 80 & 59 & 9 & VI0301_00 \\
\hline MTP12 & & 83 & 37 & 6 & $\begin{array}{c}\text { VI0336_00, VI0336_01, } \\
\text { VI0336_02, VI0336_03, } \\
\text { VI0336_04, VI0336_05, } \\
\text { VI0336_08 }\end{array}$ \\
\hline MTP13 & & 126 & 12 & 6 & \\
\hline MTP14 & & 105 & 15 & 3 & VI0381_00, VI0392_05 \\
\hline 'MTP15 & & 3 & 1 & & \\
\hline MTP16 & & 2 & 16 & & \\
\hline MTP17 & 62 & 9 & 2 & & \\
\hline MTP18 & 10 & 26 & & & \\
\hline MTP19 & & & & & \\
\hline МТР20 & 12 & & 3 & & \\
\hline
\end{tabular}

\section{Total $=1450$}

492

493

494

495

496

497

498

499

500

501

502

503

504

505

506

507

508

Table 1: A summary of the number of observations used in this analysis, their medium term planning (MTP) ID, and integration times. An MTP equates to a calendar month of observations. There are a total of 82 Northern Hemisphere observations.

Figure 1: The 2.18 to $2.50 \mu \mathrm{m}$ thermal emission from the deep atmosphere of Venus. The result of increasing the $\mathrm{CO}$ abundance in the troposphere is to increase the absorption in the 2.30 to $2.42 \mu \mathrm{m}$ region. The dashed lines show the spectral location taken for this analysis.

Figure 2: A test of the Collard et al. (1993) method, using data from a typical VIRTIS observation, VI0099_02 (orbit 99, sequence 2). Left: A plot of radiances from Band 135 (2.30 $\mu \mathrm{m})$ against Band $137(2 . \overline{3} 2 \mu \mathrm{m})$, showing the branching, indicative of increased CO, and the arbitrary bisecting straight line (red). Top right: The displacement of the points from the line as a function of latitude Bottom right: The $2.3 \mu \mathrm{m}$ cloud opacity radiances, with higher values indicating smaller cloud opacity.

Figure 3: Same observation as Fig. 1, showing (top) The ratio of raw Band 135/Band 137 radiances, against latitude, (bottom) $2.3 \mu \mathrm{m}$ cloud opacity radiances. The solid lines indicate the 
zonal means, whilst the error bars are the $1 \sigma$ standard deviations from the zonal mean. No correction for the wavelength shift has been made here.

Figure 4: The 2.30/2.32 $\mu \mathrm{m}$ wavelength pair used in this analysis as a function of cloud thickness, plotted against 2.30 peak radiance $\left(\mathrm{W} / \mathrm{m}^{2} / \mathrm{sr} / \mu \mathrm{m}\right)$, using different cloud modes in the forward model. Dotted vertical line indicates approximately where the radiance ratio exceeds $10 \%$ error and depends evermore strongly on the cloud thickness. The $2.30 / 2.33 \mu \mathrm{m}$ and $2.30 / 2.31 \mu \mathrm{m}$ wavelength pairs are also plotted, using Mode2', but are not used in the analysis.

Figure 5: The effect of emission angle on the ratio for different assumed a priori cloud, temperature and $\mathrm{CO}$ profiles. For all assumed profiles, the effect of the emission angle is less than $1 \%$.

Figure 6: The conversion profile relating the radiance ratio value, to $\mathrm{CO}$ concentration. (Inset) The assumed $\mathrm{CO}$ vertical profile used to create the linear trend.

Figure 7: A comparison, using the same observation VI099_02, of the zonal mean ratio derived in this analysis (black) with the zonal mean CO abundance from spectral fitting by Tsang et al. (2008) (red).

Figure 8: Southern Hemisphere observations VI0336_00 (top) and VI0392_05 (bottom), with their associated $2.3 \mu \mathrm{m}$ radiances (left) and the ratio at 2.30/2.32 (right). In regions where the $2.3 \mu \mathrm{m}$ radiances drops below $0.02 \mathrm{~W} / \mathrm{m}^{2} / \mathrm{sr} / \mu \mathrm{m}$, the ratio is sensitive to cloud opacity variations and have been masked out (white areas). Above this value, the ratio map is essentially free of cloud features and shows the CO abundance at $\sim 35 \mathrm{~km}$. The general equator-pole increase is clear, and some longitudinal variability can also be seen. $0^{\circ}$ longitude is marked by thick dashed line.

Figure 9: Southern Hemisphere observations VI0301_00 (top) and VI0381_00 (bottom), with their associated $2.3 \mu \mathrm{m}$ radiances (left) and the ratio at $2.30 \overline{0} / 2.320$ (right). In contrast to the observations presented in Fig. 7, the equator-pole increase in $\mathrm{CO}$ is absent, showing great temporal variability in the $\mathrm{CO}$ abundance between the two figures. Regions where the $2.3 \mu \mathrm{m}$ radiance drops below 0.02 $\mathrm{W} / \mathrm{m}^{2} / \mathrm{sr} / \mu \mathrm{m}$ have been masked white on the radiance ratios. $0^{\circ}$ longitude is marked by thick dashed line.

Figure 10: (top) Ratio of radiances at $2.30 \mu \mathrm{m} / 2.32 \mu \mathrm{m}$ for the observation shown, and (bottom) the $2.3 \mu \mathrm{m}$ radiances. It can be seen that the cloud opacity variations at $2.3 \mu \mathrm{m}$ are well decoupled from the $2.30 / 2.32 \mu \mathrm{m}$ ratio. It also shows the expected CO latitudinal trends. Thick lines indicate the zonal mean, with thin lines showing the $1 \sigma$ variance from the mean.

Figure 11: Ratio of radiances at $2.30 \mu \mathrm{m} / 2.32 \mu \mathrm{m}$ against latitude, and the corresponding $\mathrm{CO}$ abundance near $35 \mathrm{~km}$ in units of ppmv using the linear trend in Fig. 5. The trends show variations in the magnitude of the CO maximum and its location in the Northern and Southern hemispheres. 
551 Only zonal means are plotted to avoid confusion. CO abundances have not been plotted where the 552 corresponding $2.3 \mu \mathrm{m}$ radiance drops below the threshold value of $0.02 \mathrm{~W} / \mathrm{m}^{2} / \mathrm{sr} / \mu \mathrm{m}$.

553

554 Figure 12: Ensemble zonal mean trends of $\mathrm{CO}$ retrieved in this study using the band ratio technique 555 from all 1450 observations. Zonal mean values have not been plotted where the corresponding 2.3 $556 \mu \mathrm{m}$ radiance drops below the threshold value of $0.02 \mathrm{~W} / \mathrm{m}^{2} / \mathrm{sr} / \mu \mathrm{m}$. 


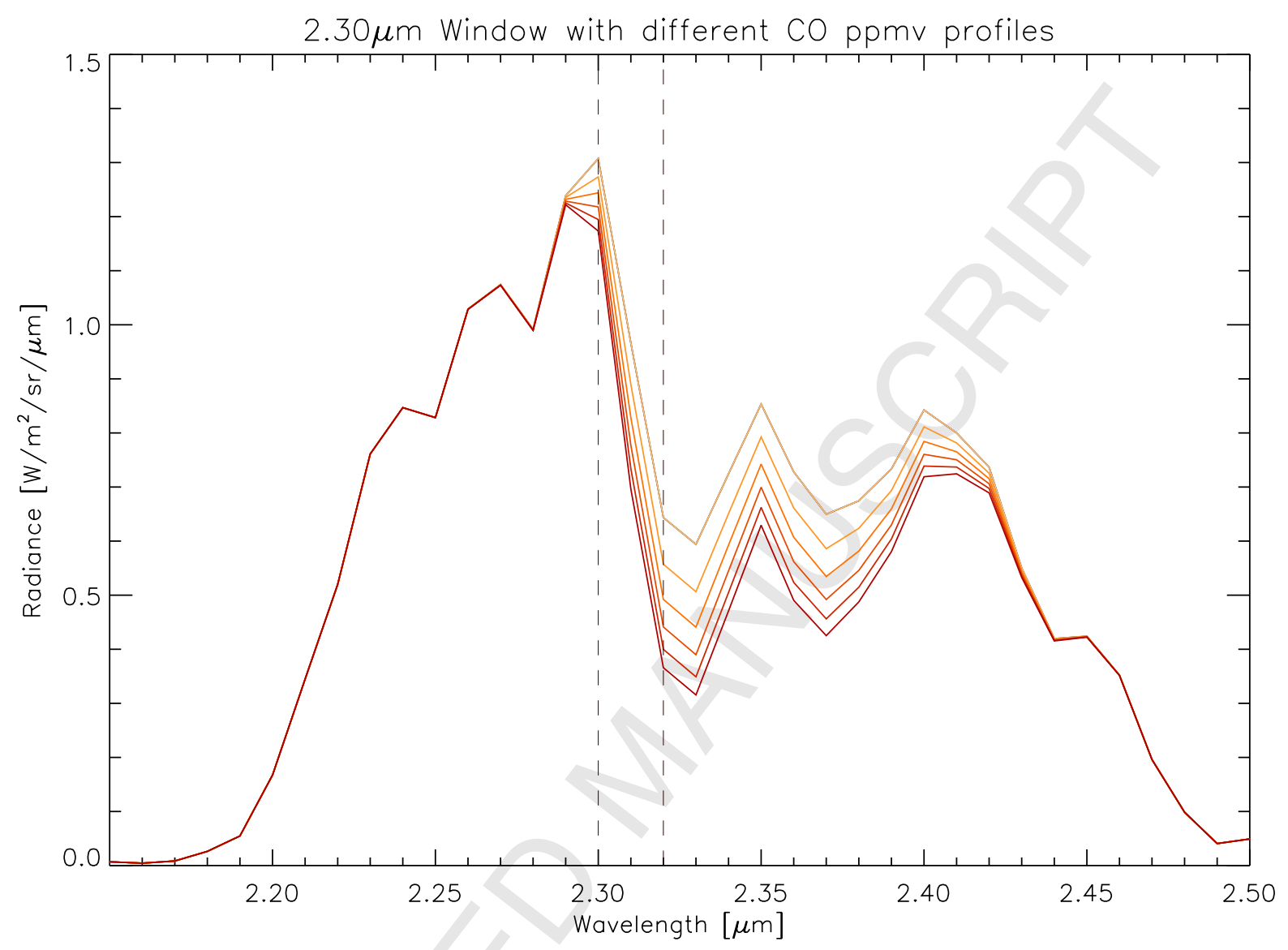



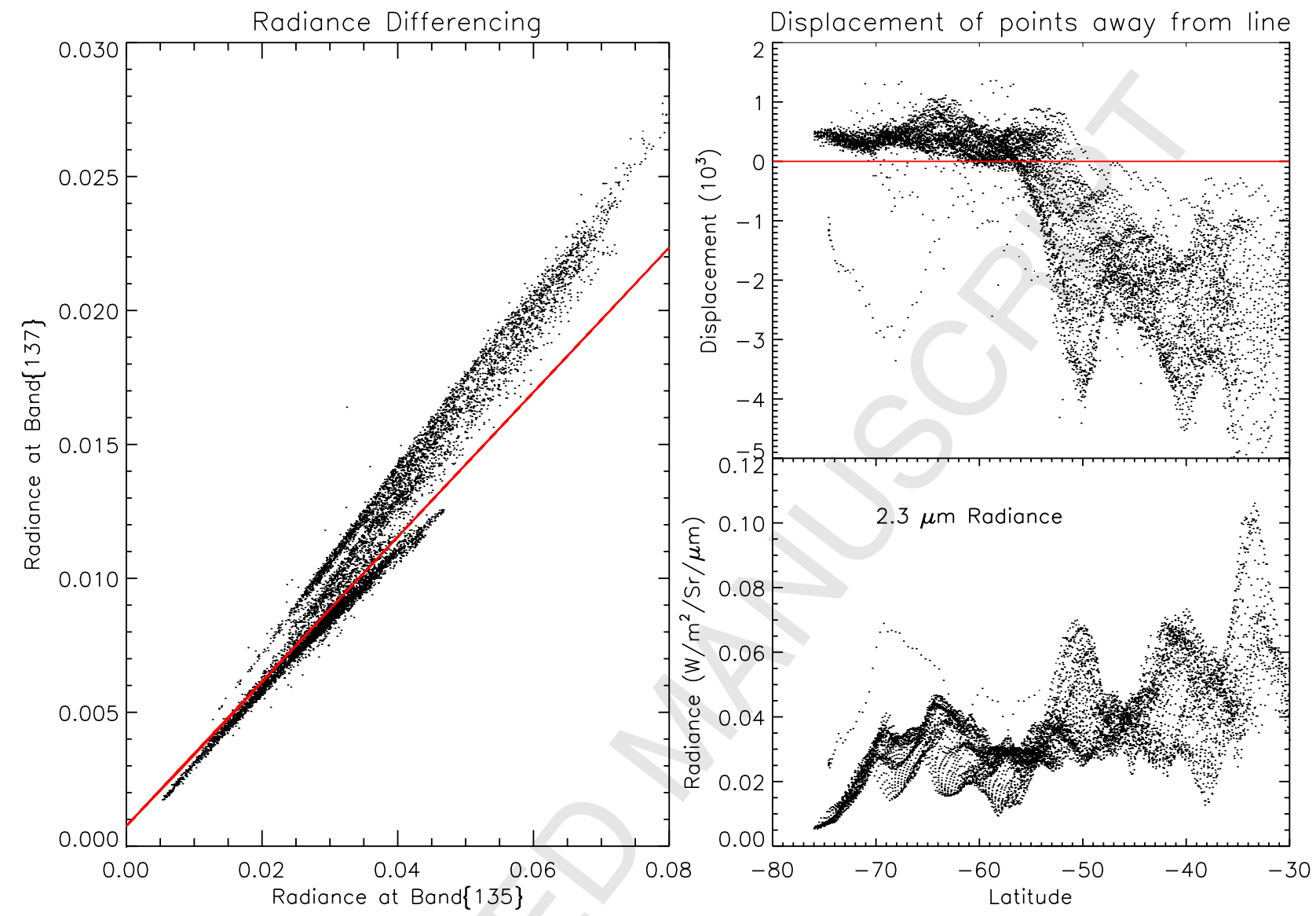


\section{ACCEPTED MANUSCRIPT}
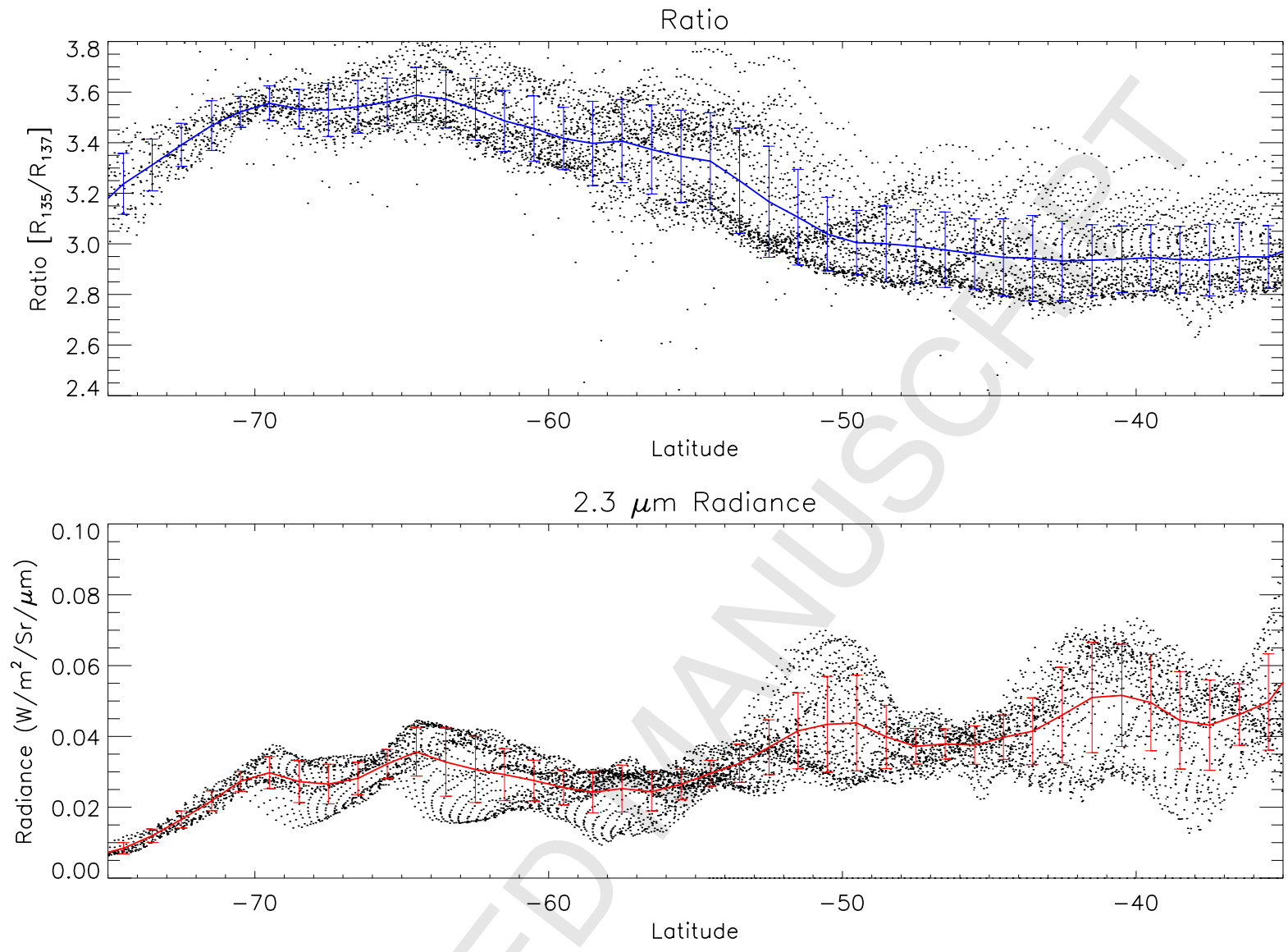


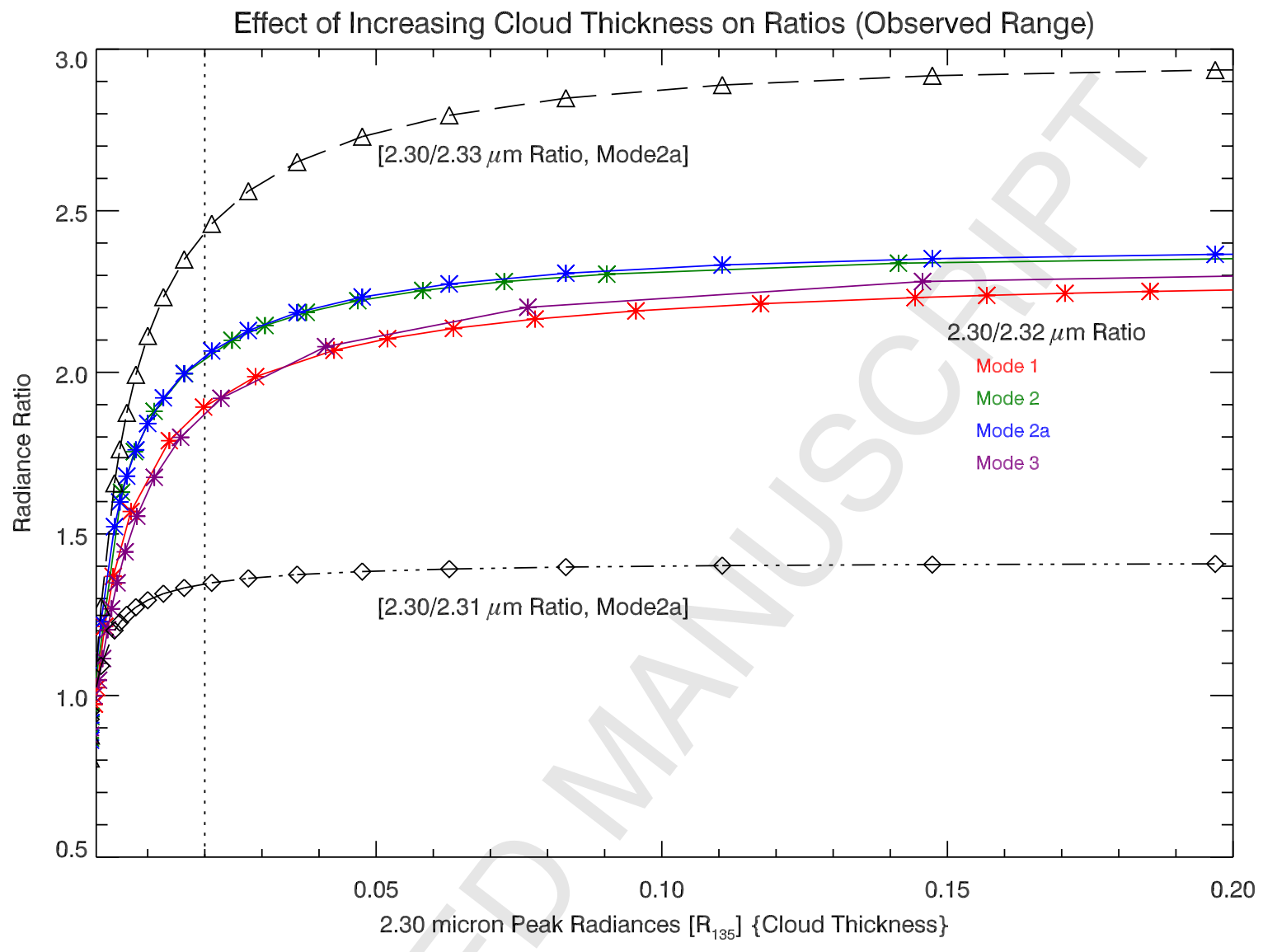




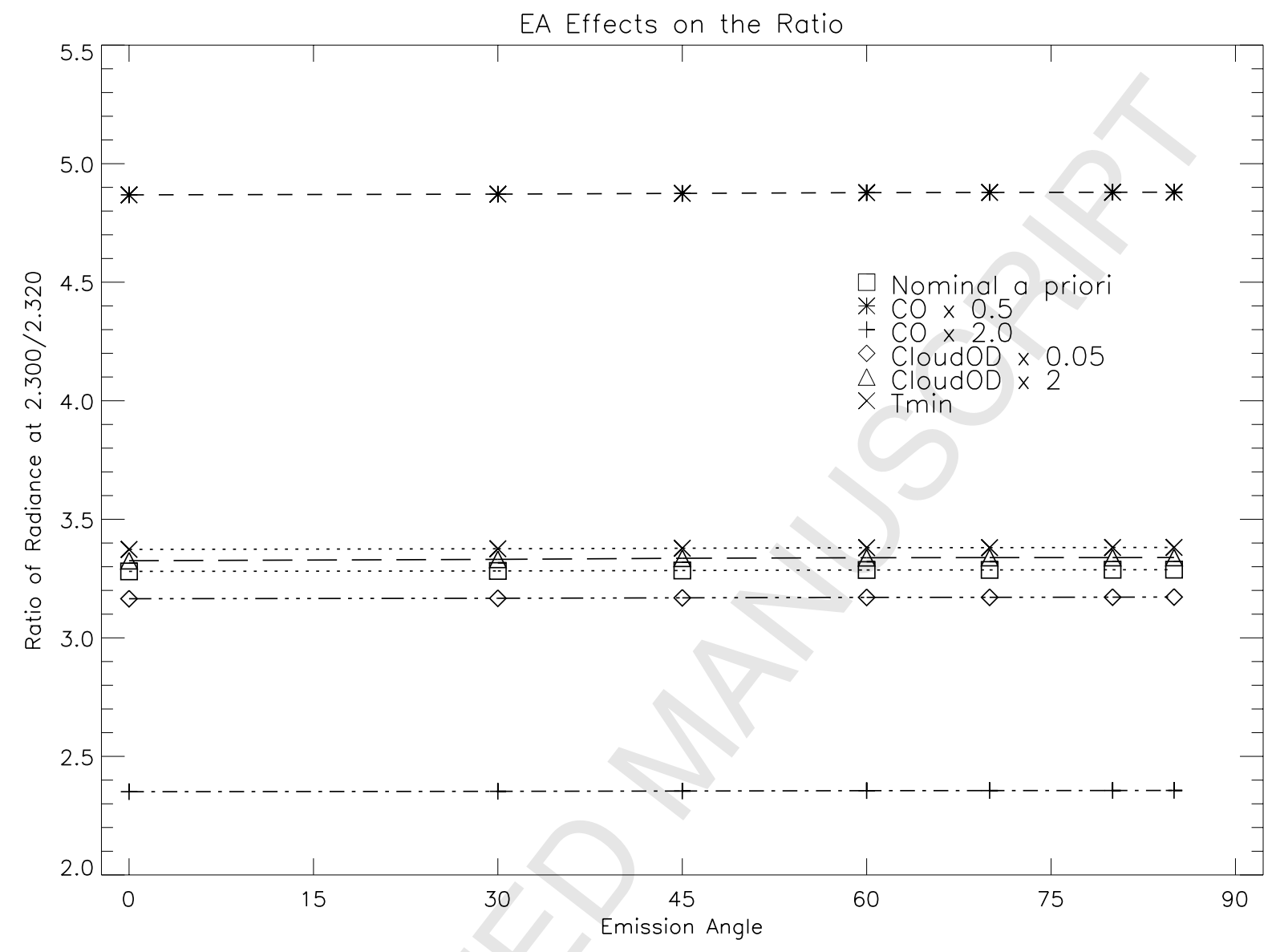




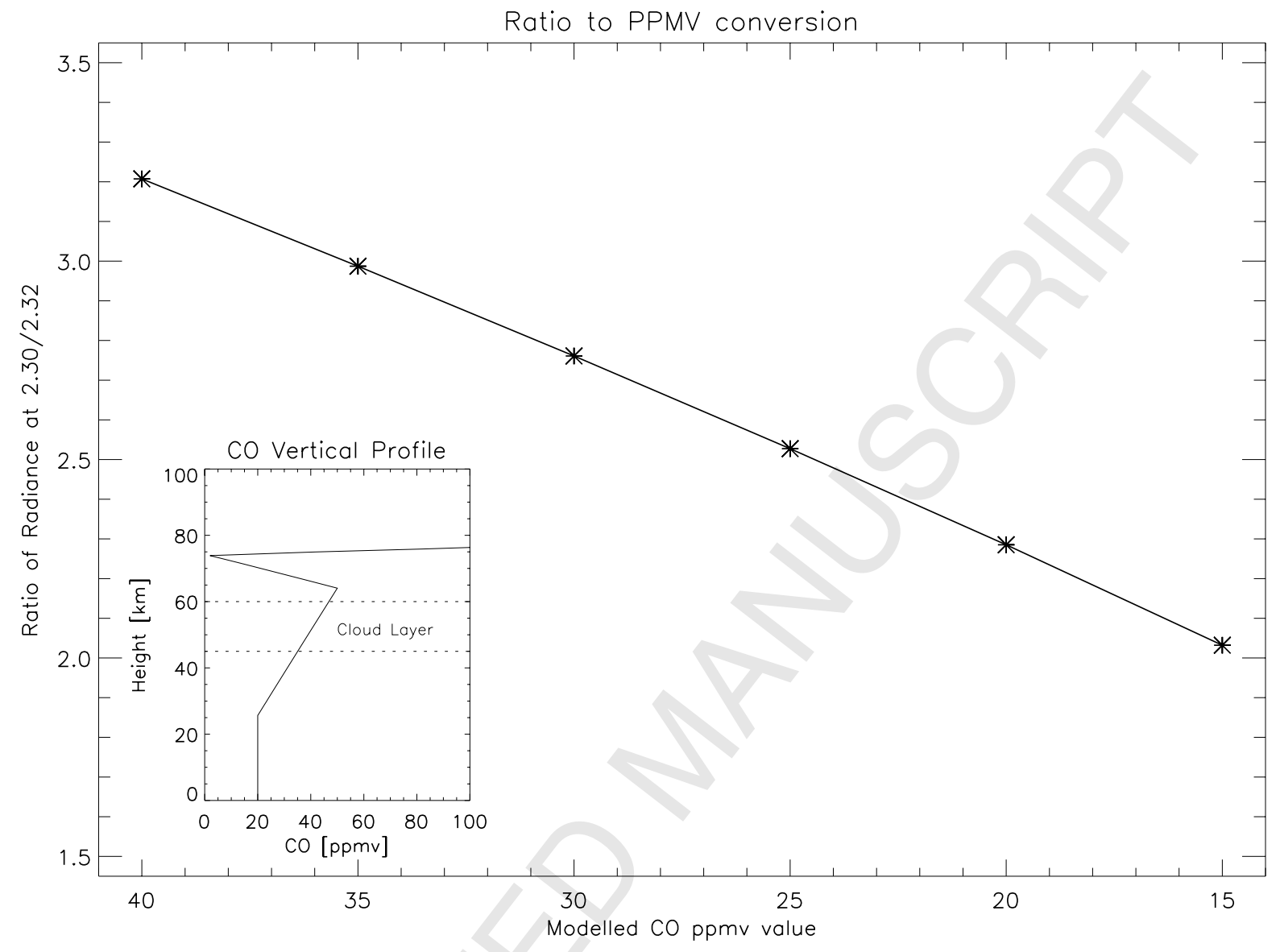




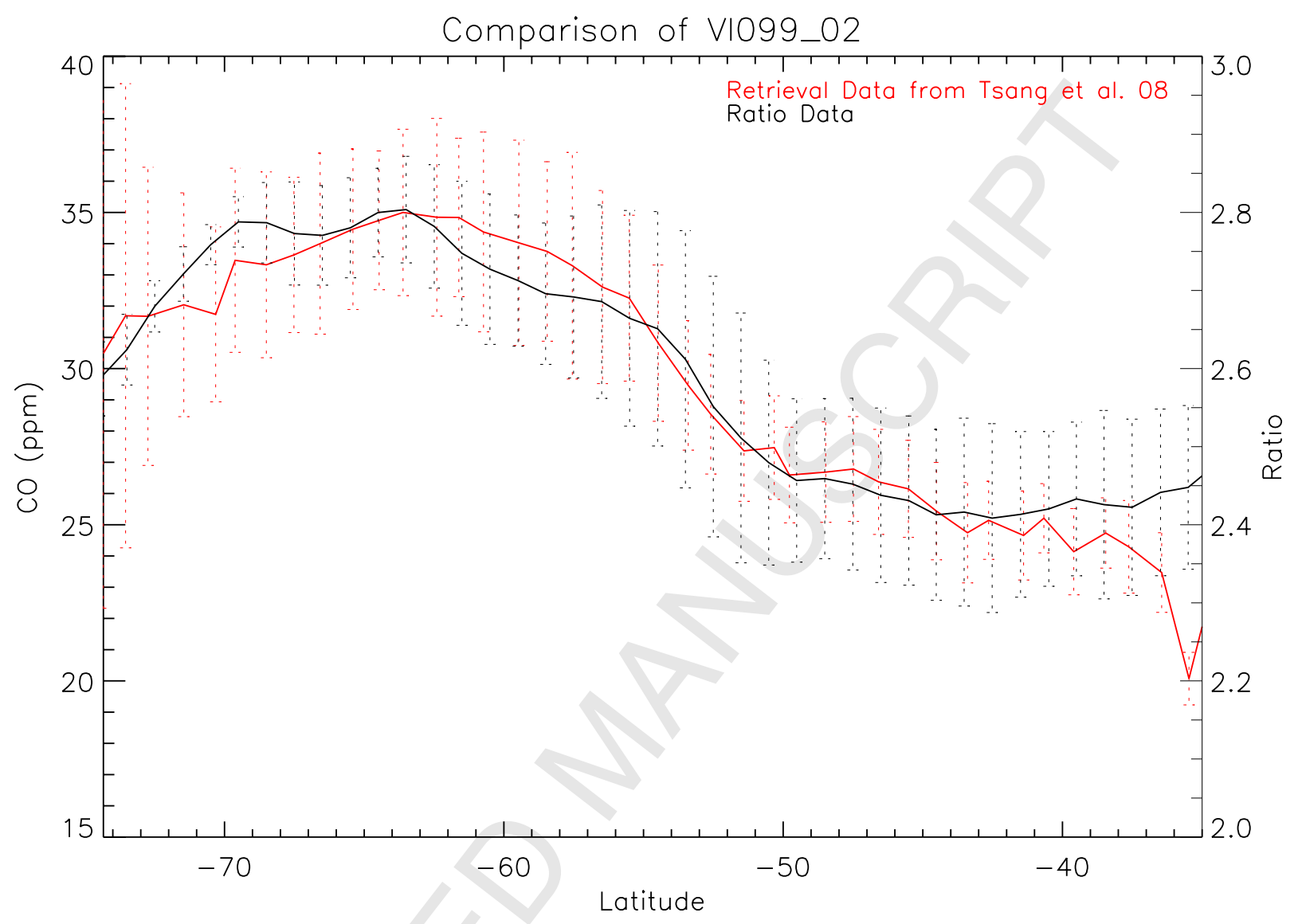




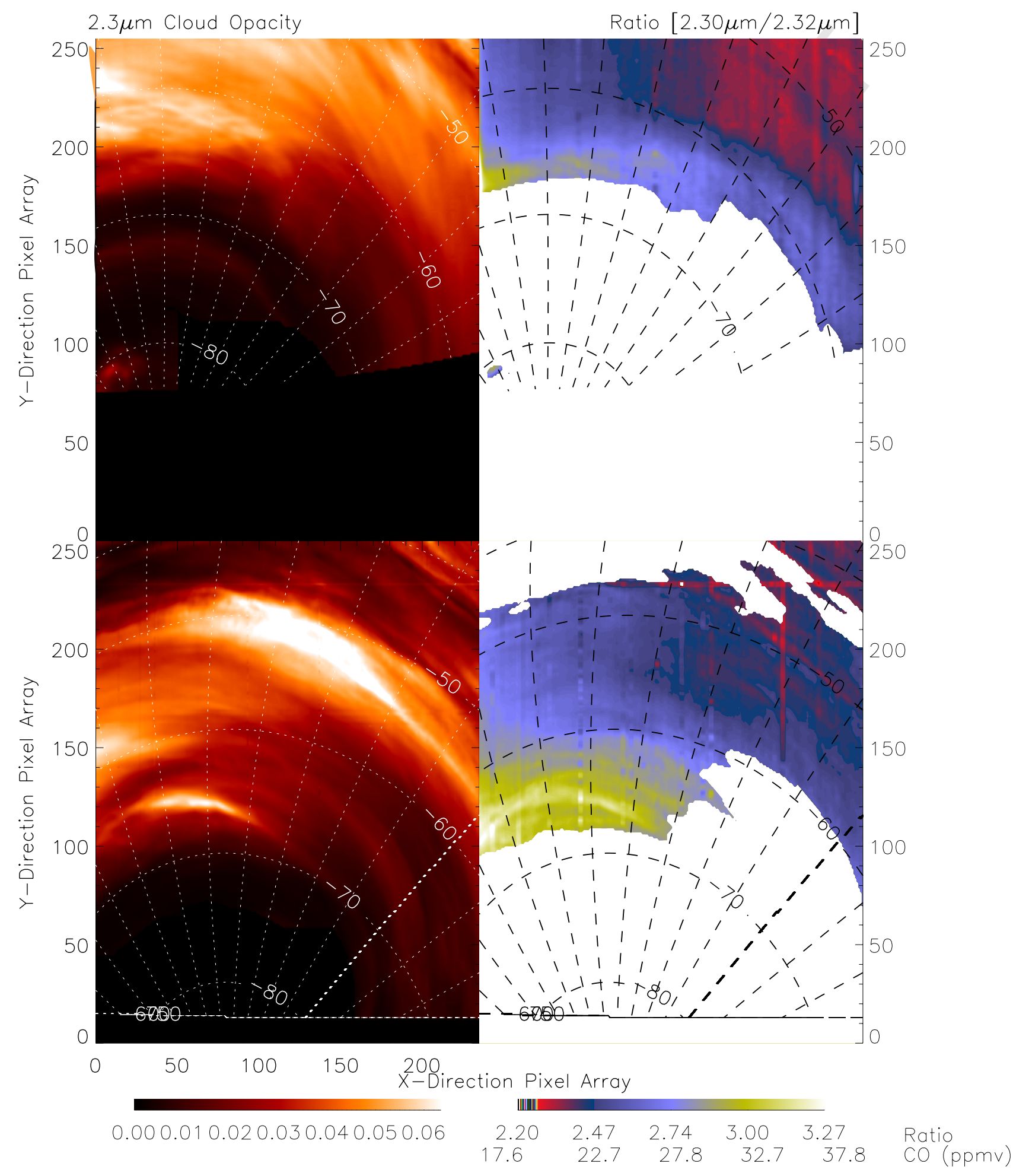




\section{ACCEPTED MANUSCRIPT}

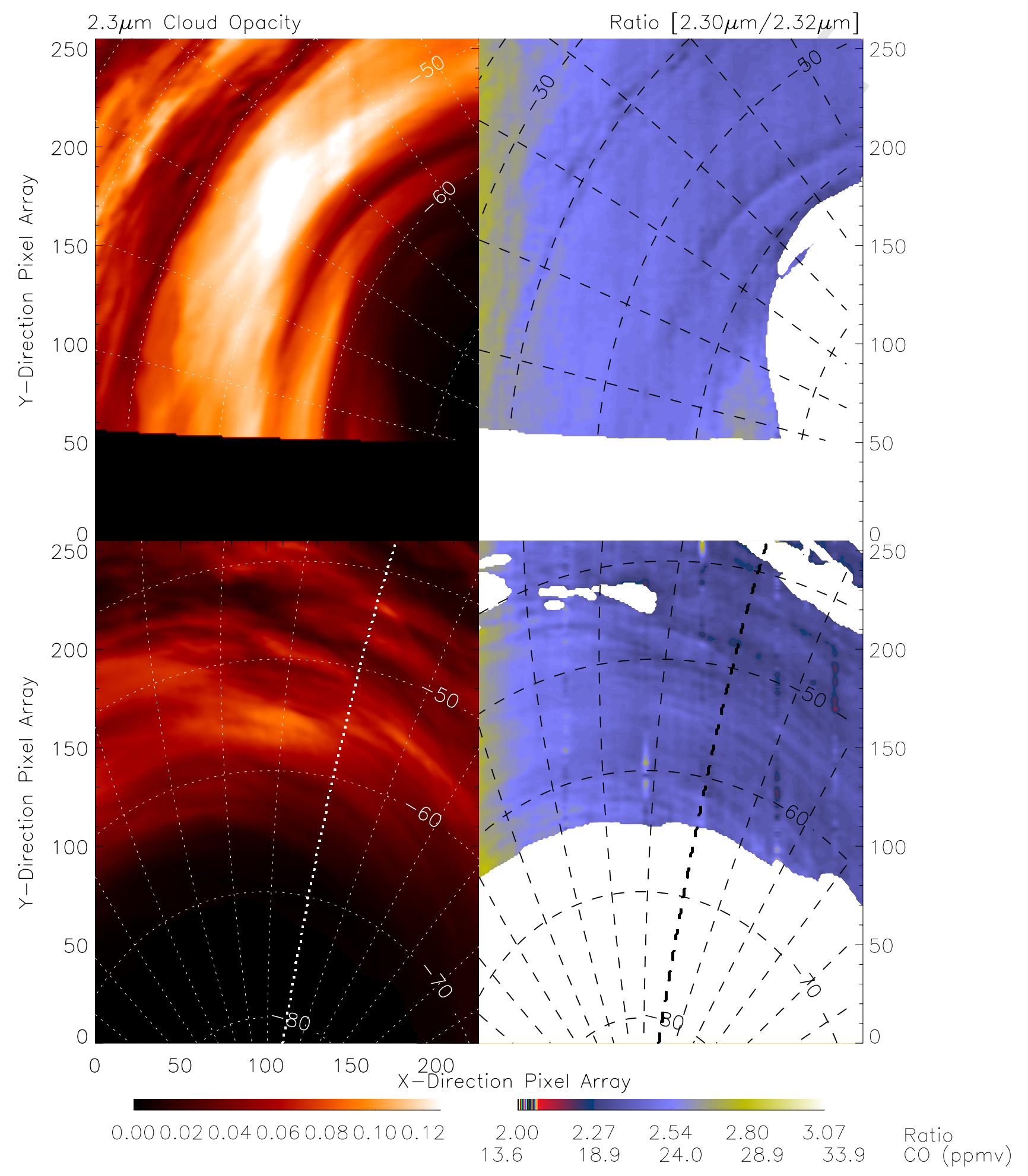



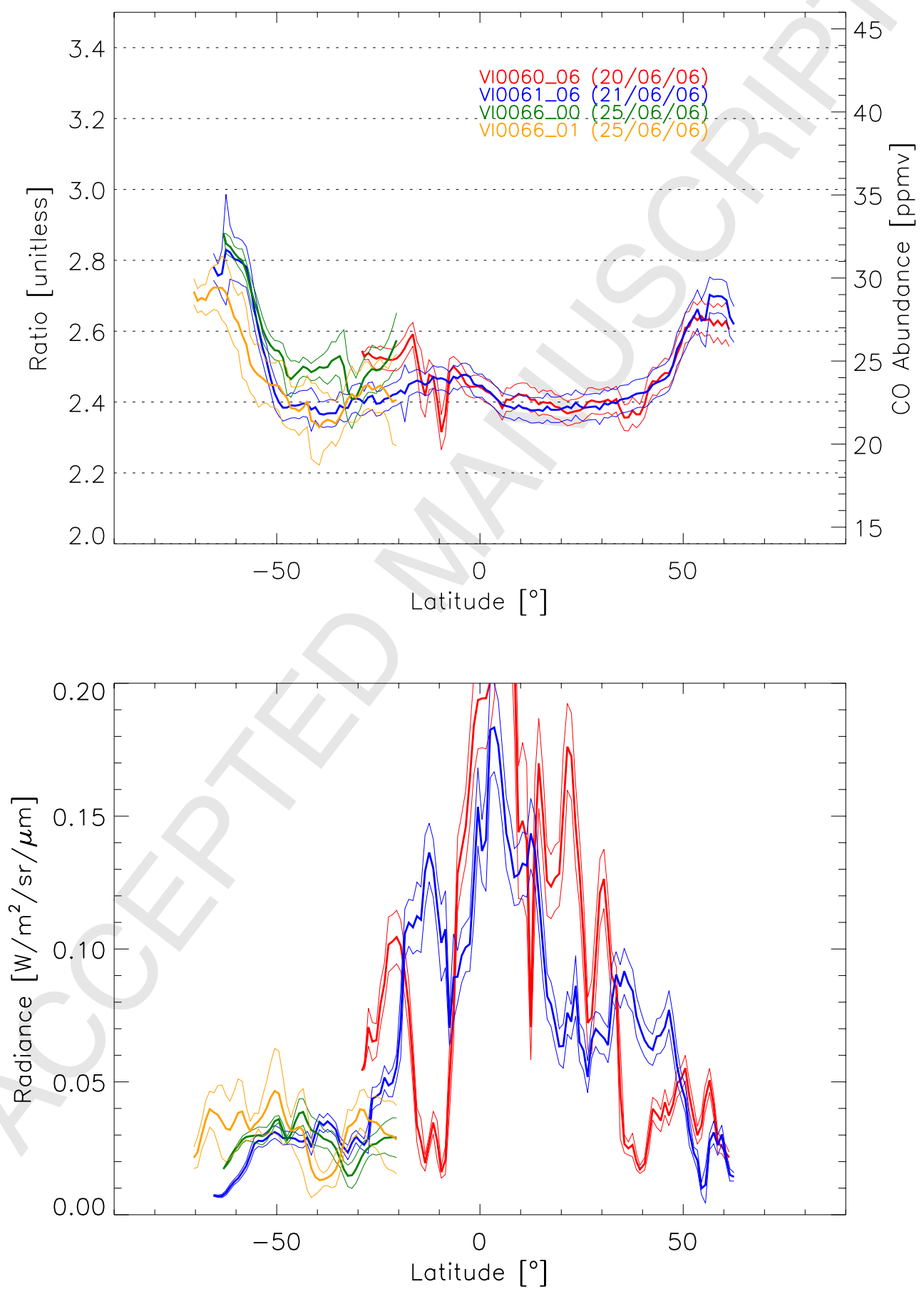

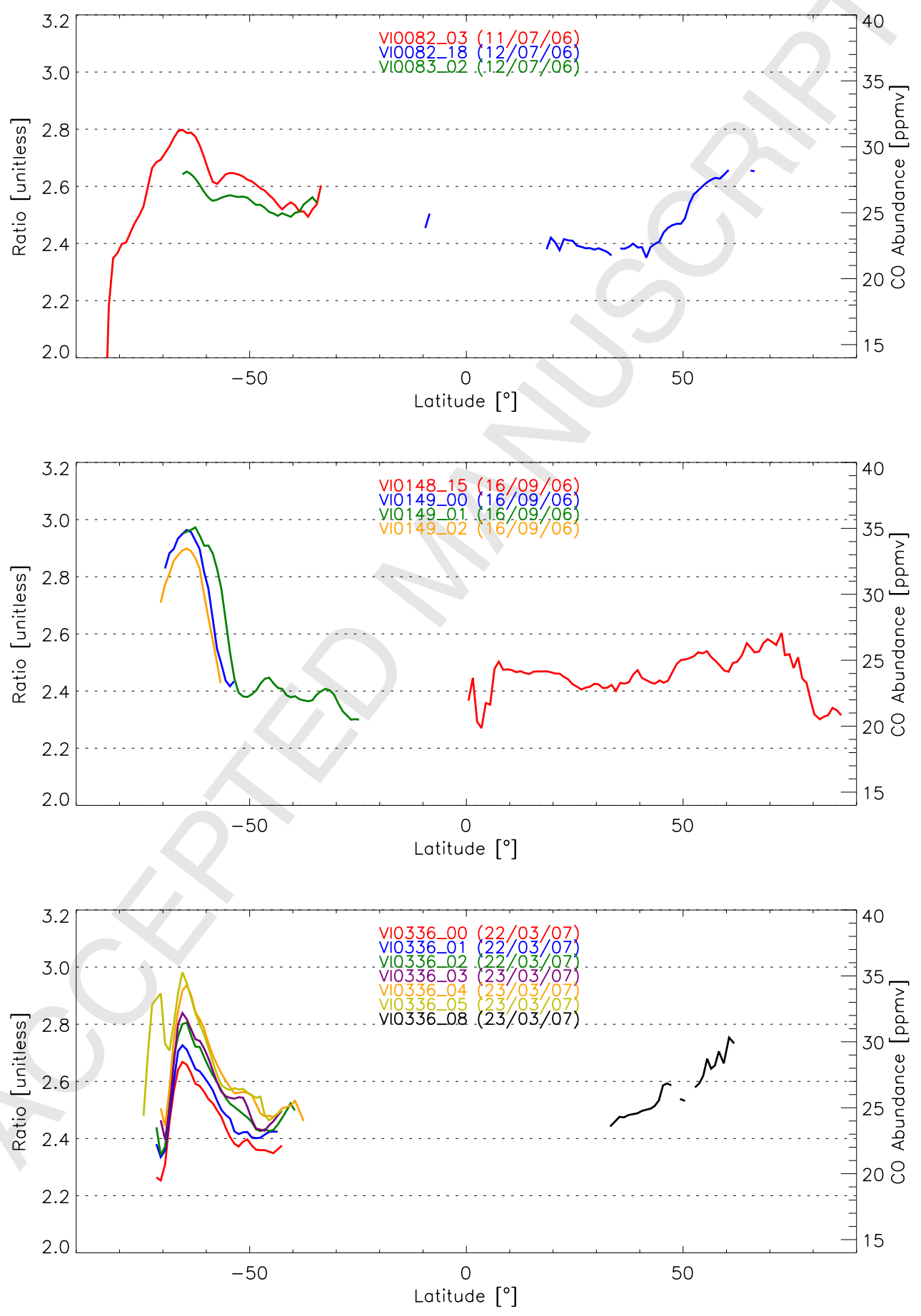


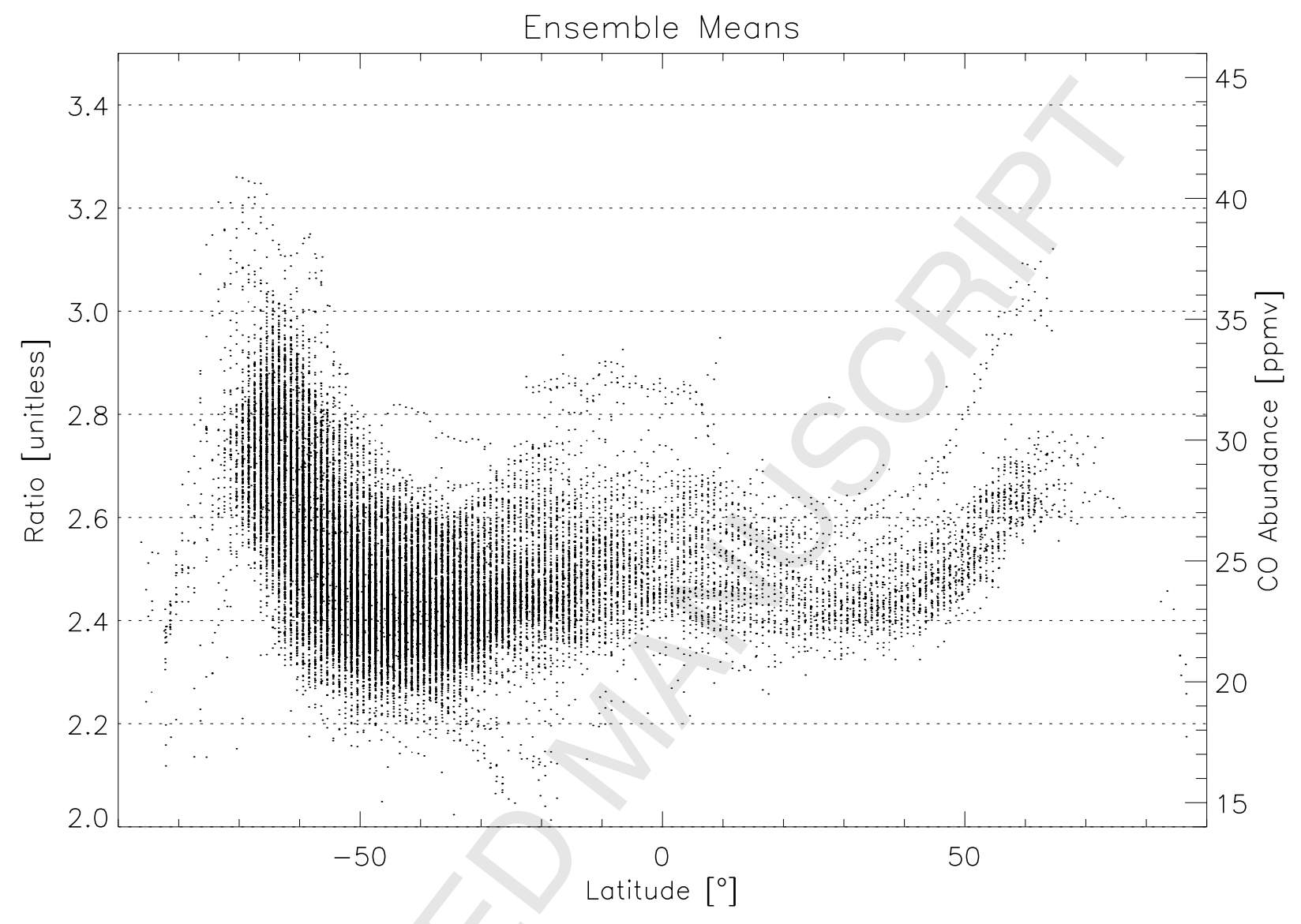

